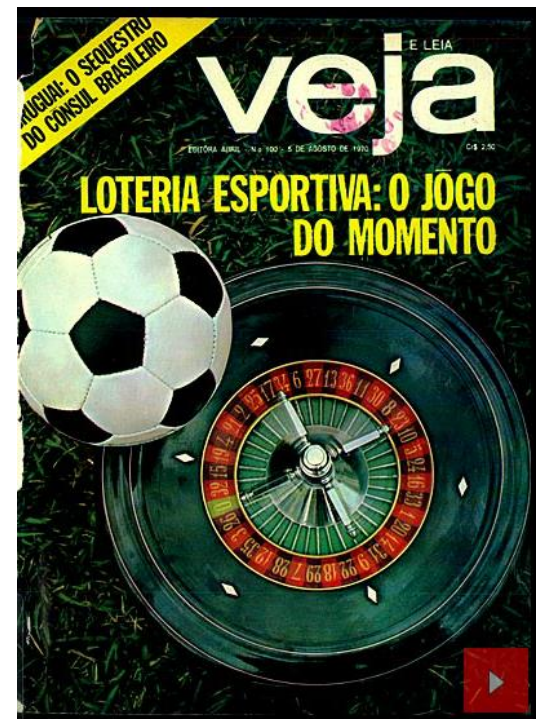

\title{
Jogada de Médici: o uso da loteria esportiva pelo regime militar brasileiro
}

"Jogada de Médici": the use of the "sports lotery" by the Brazilian military regime

Patrícia Fino ${ }^{1}$ Helio Hintze ${ }^{2}$

\section{Resumo}

Este artigo apresenta uma investigação sobre um tema ainda inédito na academia: a Loteria Esportiva como estratégia de governo dos militares. O corpus é composto por matérias sobre a Loteria Esportiva de todas as edições do ano de 1970 desde sua regulamentação em 25/03/1970, totalizando 40 números da revista Veja. A Metodologia utilizada está dividida em duas etapas: 1) levantamento das matérias publicadas na revista Veja sobre o tema; 2) apresentar, à luz do referencial da Análise Crítica de Discursos (FAIRCLOUGH, 2008; VAN DJIK, 2008), uma análise sobre o tema. Os resultados de nossas análises permitiram compreender parte dessa estratégia, além de indicar a relevância do tema, uma vez que 45\% dos exemplares analisados tinham uma ou mais matérias sobre o assunto.

Palavras-chave: Loteria Esportiva. Futebol. Ditadura Militar. Revista Veja.

\begin{abstract}
This article presents an investigation about a still unpublished theme in the academy: the "Sports Lottery" as strategy of military government. The corpus is composed of material on the "Sports Lottery" of all the editions of the year of 1970 since its regulation on 03/25/1970, totaling 40 issues of Veja magazine. The Methodology used is divided into two stages: 1) survey of the articles published in Veja magazine on the subject; 2) to present, in the light of the Critical Discourse Analysis framework (FAIRCLOUGH, 2008; VAN DJIK, 2008), an analysis of the topic. The results of our analyzes allowed to understand part of this strategy, besides indicating the relevance of the theme, since $45 \%$ of the analyzed copies had one or more subjects on the subject.
\end{abstract}

Keywords: Sports Lottery. Soccer. Military dictatorship. Veja.

\footnotetext{
${ }^{1}$ Doutora em Ciências (Ecologia Aplicada) e mestre em Desenvolvimento Regional e Meio Ambiente. Email : patyfino@gmail.com

${ }^{2}$ Doutor em Ciências (Ecologia Aplicada) e Mestre em Ecologia Aplicada pelo Programa Interdisciplinar em Ecologia Aplicada - USP; pós-doutorado em Economia, Administração e Sociologia - USP; Atualmente, é educador Fazer Pensar - Formação de Pessoas. Universidade Metodista de Piracicaba, Faculdade de Gestão e Negócios. Rodovia do Açúcar Km 156 s/n. Taquaral - Piracicaba, SP - Brasil. Email: heliohintze@yahoo.com.br
} 


\section{Introdução}

No ano de 1970, reconhecidamente um dos mais repressivos dos 21 anos nos quais perdurou a Ditadura Militar, o Brasil foi tricampeão da Copa do Mundo de Futebol. Mais que a obtenção do principal título dessa modalidade, a vitória converteu-se numa espécie de ópio à população brasileira. A conquista da taça Jules Rimet foi utilizada pelo governo para divulgar a imagem de um país vencedor e, assim, encobrir a repressão do regime militar no governo Médici (1969 - 1974), legitimando o regime de exceção vivido no Brasil perante a comunidade nacional e internacional.

Cinquenta anos depois do Golpe Civil-Militar, no ano de 2014, o Brasil (chamado pelo material publicitário do atual governo de 'Pátria de Chuteiras') sedia a Copa do Mundo de Futebol. Este panorama traz a necessidade de novas pesquisas acadêmicas, as quais devem investigar este importante momento da história recente do país, com o intuito de preencher lacunas vitais para a compreensão da sociedade em que vivemos hoje. Neste artigo, buscou-se investigar os temas 'ditadura militar' e 'futebol', perante um prisma ainda inédito na academia: o uso da Loteria Esportiva como estratégia de governo dos militares.

O investimento massivo por parte do governo Médici para o sucesso de tal loteria foi algo expressivo naquele período. Isso despertou o interesse dos autores para uma investigação sobre tal temática. Sendo assim, o objetivo deste artigo é investigar quais foram os objetivos e algumas das estratégias utilizadas pelo governo federal para a adesão da população pelo uso das Loterias Esportivas. Partimos do pressuposto de que, o governo federal, sob a direção de Médici, valeu-se de um discurso ufanista sobre o Brasil como país do futebol para incentivar a adesão da população à Loteria, no intuito de usá-la para obter diversos benefícios.

Este artigo está dividido em quatro seções. Na primeira, 'Ditadura Militar e Futebol no Brasil', procurou-se contextualizar o período em que o Brasil foi governado por um regime de exceção e apresentar parte da estratégia utilizada por tais governos em torno do futebol como discurso ufanista; na segunda 'A Loteria Esportiva', é apresentado um breve histórico sobre o jogo criado na década de 1970 e uma revisão de literatura, indicando quais foram os objetivos do Governo Federal com a criação e implantação da Loteria Esportiva; na terceira, propomos e apresentamos os dispositivos teórico- 
analíticos, contextualizamos o veículo do qual extraímos o corpus para a análise e apresentamos os procedimentos metodológicos; na quarta, é apresentada a análise dos dados. Por fim, com base nos resultados alcançados, apresentamos considerações e críticas finais.

\section{Ditadura Militar e Futebol no Brasil}

Assim como em outros países da América Latina, o Brasil viveu entre as décadas de 1960 e 1980 um período dominado pelo regime militar: violência, tortura, impunidade e desigualdade são alguns fatos que podem ser associados ao período ditatorial quefoi instalado no Brasil, em acordo com uma geopolítica internacional, com o Golpe de 1964.

A amplitude dos malefícios causados durante aquele período foi incomensurável. Chiavenato (1995, p.5) menciona que "a ditadura destruiu a economia, institucionalizou a corrupção e fez da tortura uma prática política. Envileceu a nação e abalou o caráter brasileiro. Alienou as novas gerações, tornando-as incapazes de entender a sociedade em que vivem".

Durante aquele período foi colocada em prática a Política de Segurança Nacional, que foi responsável por legitimar a criação dos atos institucionais. Ao todo, foram criados 17 Atos, que permitiram legalizar arbitrariedades em prol dos objetivos ditatoriais. O primeiro foi criado logo após a posse do General Castelo Branco: o AI-1 lhe dava o direito de cassar mandatos parlamentares e de suspender direitos políticos de cidadãos (GASPARI, 2002).

Em dezembro de 1968, iniciou-se o período mais duro da ditadura militar brasileira. O AI-5 foi instituído como resposta aos movimentos sociais de oposição à ditadura e decretou a censura a jornais, revistas, livros, peças de teatro e músicas, tornando-se, dessa forma,

a expressão mais acabada da ditadura militar brasileira. Vigorou até dezembro de 1978 e produziu um elenco de ações arbitrárias de efeitos duradouros. Definiu o momento mais duro do regime, dando poder de exceção aos governantes para punir arbitrariamente os que fossem inimigos do regime ou como tal considerados. (D'ARAÚJO, 2010, p.1)

Mesmo com o AI-5 em vigor, os movimentos de oposição e resistência foram crescentes. Lutas clandestinas, greves e manifestações resultaram no aumento da repressão e da violência. Diante da oposição intensa ao regime, a estratégia encontrada 
pelo governo foi intensificar o controle ideológico do povo por meio da mídia para assim conseguir seu apoio. Neste período também foi promovida a (falsa) imagem do Milagre Econômico, amplamente divulgada por todos os tipos de mídia. O país era apresentado com jargões do tipo "Modelo Brasileiro", "Brasil Grande", "Grande Potência", e "Gigante da América Latina”, designações que faziam parte desta sustentação ideológica. Assim, temas nacionalistas e de otimismo foram amplamente divulgados (MARCONI, 1980; FICO, 1997; GRAF, 2003; GARCIA, 2005) tanto nas propagandas com marcas oficiais, quanto nas mais diversas notícias da época.

Durante os anos de 'milagre', o governo Médici procurou criar um clima de triunfalismo ufanista em torno de idéia de que o Brasil era um país próspero e tranqüilo ${ }^{3}$, um país mágico que até o fim do século $\mathrm{XX}$ teria garantido o seu ingresso no mundo desenvolvido como 'Grande Potência' (HABERT, 2003, p.19).

Números promissores devido ao desenvolvimento industrial eram constantemente divulgados, porém tal crescimento foi alicerçado no capital estrangeiro em detrimento das empresas nacionais, promovendo uma intensa desigualdade social. $\mathrm{O}$ expressivo aumento da dívida externa também foi consequência desse período, muitas vezes contraída para comprar equipamentos ultrapassados em seus países de origem ou empresas multinacionais instaladas no Brasil que já não rendiam tantos lucros e estavam sucateadas.

Assim como o "milagre econômico", o futebol também foi tema estrategicamente escolhido para escamotear a repressão e promover o clima de otimismo em um país com tamanhas singularidades. O futebol, em consonância com a ideologia da "unidade nacional", atingiu a quase totalidade da população (fato que merece atenção, pois dificilmente outro tema despertaria tal interesse e comoção se pensarmos nas proporções geográficas e diferenças socioculturais que o Brasil condensa) servindo aos interesses dos governos militares relacionados ao controle ideológico.

\subsection{Futebol}

Historicamente, no caso brasileiro, pode-se pensar no futebol de duas maneiras: 1) como importante elemento da cultura brasileira e 2) como meio de transmissão

\footnotetext{
${ }^{3}$ Optamos por seguir a ortografia original dos excertos analisados para mantermo-nos fieis ao material coletado - os autores.
} 
ideológica . O futebol, representante da brasilidade como elemento da cultura nacional, não é por si só ideológico, mas torna-se na "medida em que é utilizado em um determinado contexto social no sentido de transparecer valores e verdades de uma determinada concepção que pretende-se tornar hegemônica" (RINALDI, 2000, p. 169).

Neste sentido, o futebol foi peça chave no processo de ideologização executada pelos militares. As características do esporte permitiram que tal tema fosse trabalhado de maneira a contribuir e reforçar a ideologia do período, relacionando-o ao projeto de construção de um ideal de identidade nacional.

Faz-se necessário lembrar que o gosto pelo futebol era bastante popular mesmo antes do golpe de 1964, sendo este ampliado e redirecionado aos propósitos militares. Assim, os discursos promovidos pelo governo a respeito do futebol buscavam primeiramente ampliar a 'paixão' pelo esporte, valendo-se dos meios de comunicação, assim como citou Rinaldi ao dizer que "a motivação dos torcedores passa a ser cada vez mais incitada pela imprensa esportiva, e os torcedores passam a torcer com uma paixão e envolvimento cada vez maior. (2000, p. 169)".

Um exemplo clássico foi o jingle "Pra frente Brasil", inicialmente criado para propaganda de uma cervejaria (LUNA, 2011), foi utilizado politicamente pelo governo Médici. Abaixo segue parte da letra:

Noventa milhões em ação / Pra frente Brasil, no meu coração / Todos juntos, vamos pra frente Brasil / Salve a seleção!!! / De repente é aquela corrente pra frente, parece que todo o Brasil deu a mão! / Todos ligados na mesma emoção, tudo é um só coração! / Todos juntos vamos pra frente Brasil! Salve a seleção! (GUSTAVO, 1970, p. 1).

Os versos desta canção combinaram fatores como: ufanismo, otimismo, progresso, unidade e identidade nacional, reunidos pelo tema central futebol, que foi sistematicamente reforçado como a 'paixão nacional'. Desta forma, o jingle tornou-se um hino ideal aos interesses militares, o que justifica sua ampla utilização como música oficial no período. Segundo Mariuzzo (2010, p.1), a música transmitia a ideia de que, "assim como no esporte, com disciplina e amor à camisa, os brasileiros deveriam se unir pelo progresso, em uma 'corrente pra frente' que apaga o passado e celebra o presente e o futuro".

As vitórias advindas de tal esporte, sobretudo a Copa de 1970, foram vinculadas aos 'feitos' governamentais e à imagem do 'Brasil' que os militares desejavam divulgar. O futebol também foi utilizado no processo de formação de uma imagem 'humana' do 
presidente Médici, responsável pelo período mais repressivo da ditadura (1969 a 1974 os anos de chumbo). (CHAIM, 2014; AGOSTINO, 2004).

Emílio Garrastazu Médici, o mais algoz dos presidentes militares, era apresentado como o torcedor número um pelos variados meios de comunicação da época. Segundo Chaim,

Médici era calculista e estava pronto para usar a seu favor todos os frutos políticos que lhe poderiam ser produzidos pelo campo esportivo: em menos de quatro semanas de gestão, ele já havia conseguido se aproximar tanto do ícone nacional de maior poder simbólico no campo esportivo (Pelé) quanto do ícone nacional de maior poder de facto no campo esportivo (João Havelange). Este presidente (e seus assessores) tinha ciência da atração exercida pelo futebol junto à população, e não poupou energia para atrelar sua imagem ao esporte em geral, e principalmente à seleção nacional de futebol. (2014, p. 70).

Um exemplo notável foi a matéria de capa publicada pela revista Veja na semana seguinte a da vitória no mundial de 1970. A capa apresentava o busto do presidente junto ao título "A Nova Imagem de Médici”. (VEJA, 1970). A matéria referente à capa apresentava o título "A Imagem do Sucesso", juntamente com uma foto do presidente segurando a bandeira do Brasil nas mãos. Desta forma, a edição 95 da revista Veja afirmava que a nova imagem de Médici era a imagem do sucesso.

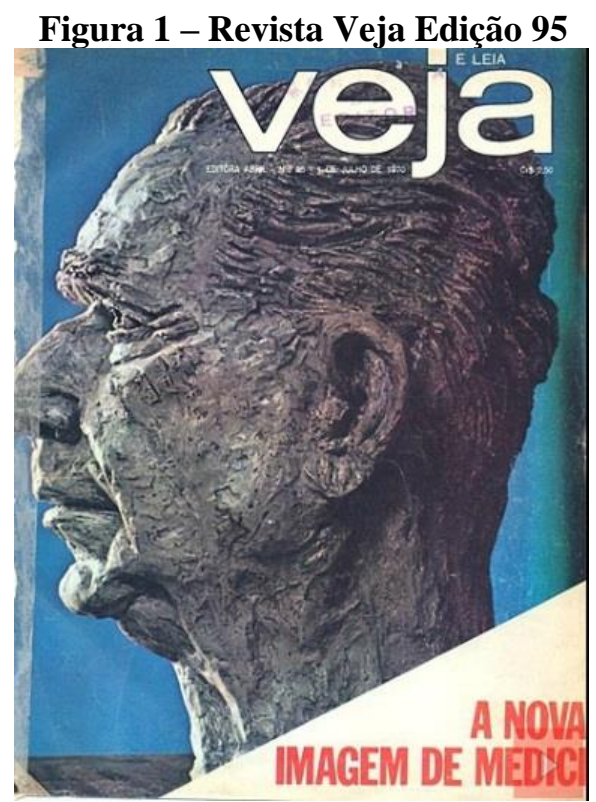

Fonte: Acervo Revista Veja, 1970 


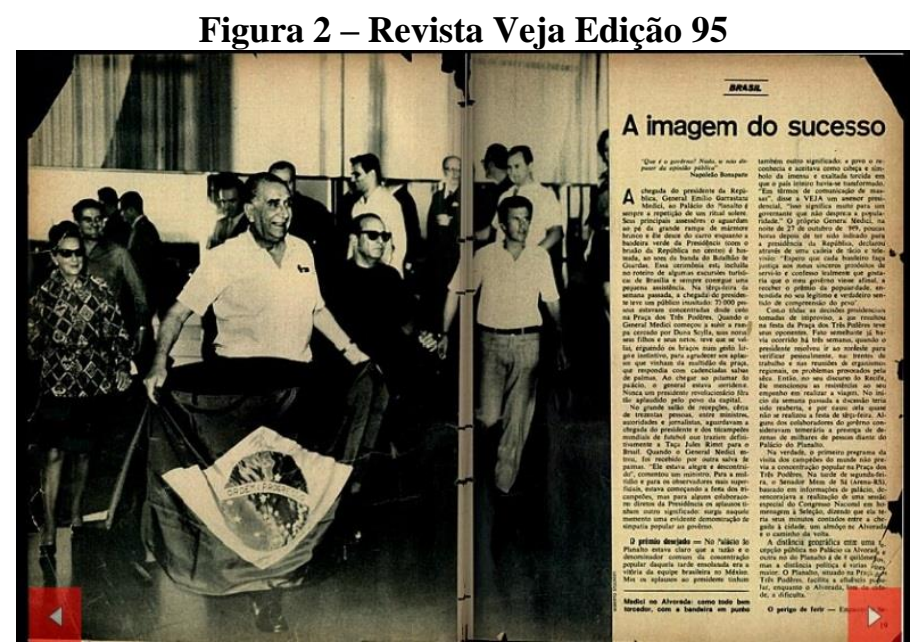

Fonte: Acervo Revista Veja, 1970

Um dos trechos da matéria diz que, Médici, ao subir a rampa do Planalto

teve que se voltar, erguendo os braços num gesto largo e instintivo, para agradecer aos aplausos que vinham da multidão da praça, que respondia com cadenciadas salvas de palmas. Ao chegar ao patamar do palácio, o general estava sorridente. Nunca um presidente revolucionário fora tão aplaudido pelo povo da capital. (VEJA, 1970, p.19).

Por este excerto infere-se o interesse da mídia governista em representar como o futebol movia a população e como os discursos emanados pelo governo eram eficientes. Isto sem dizer que a própria matéria ${ }^{4}$ reforça e divulga a imagem de um presidente humano, educado, simpático e sorridente.

Valendo-se da estrutura criada em torno do futebol e pensando em otimizar os benefícios advindos de tal tema, Médici criou oficialmente a Loteria Esportiva em 1970.

\section{A Loteria Esportiva}

Idealizada durante o governo Costa e Silva (1967 - 1969), foi no governo Médici que a Loteria Esportiva passou a existir, tanto legalmente, com a assinatura do decretolei n. 66.118, de 26 de janeiro de 1970 (VINCENZO, 2006), quanto na prática, com o primeiro concurso ocorrendo em 19 de abril de 1970 (LOTERIAS CAIXA, 2011).

\footnotetext{
${ }^{4}$ Aqui se optou por exemplificar com a matéria publicada na revista Veja, por este ser o semanário escolhido como fonte de dados para este estudo. Porém esta cena e o enfoque dado ao acontecimento foram publicados nos mais variados meios de comunicação.
} 
Dentre as especificações contidas naquele decreto-lei, a divisão do dinheiro arrecadado é um ponto que merece ser aqui destacado. Da renda bruta, 50\% do total arrecadado eram para o pagamento do(s) prêmio(s), 12\% para despesas gerais e 13\% para pagamento das comissões. Da renda líquida advinham os recursos de caráter 'social', deles $40 \%$ eram destinados à Legião Brasileira de Assistência (LBA), 30\% ao Conselho Nacional de Desportos e 30\% para o Ministério da Educação e Cultura. (DECRETO-LEI, 1970). Interessante notar que nos países europeus, nos quais o Brasil se 'inspirou' para criar a loteria esportiva, são destinados $50 \%$ de toda a arrecadação ao governo. No Brasil, entretanto, além dos $50 \%$ do valor total arrecadado, ainda é cobrado imposto sobre o prêmio pago (VINCENZO, 2006). Esta particularidade fez com que as arrecadações brasileiras fossem substancialmente maiores do que nos demais países.

A propaganda oficial trazia o slogan "Está aí a profissão mais rendosa do Brasil: palpiteiro". (PLACAR, 1970, p. 35). O texto que acompanhava a peça publicitária dizia:

Não dê mais palpites de graça. Agora seu palpite vale muito dinheiro. Indique quem vai ganhar os jogos da semana. Ou se vai haver empates. Num mesmo jogo, você pode dar palpite duplo. E até palpite triplo: ganha este, ganha aquêle e empatam. Pode fazer isto com quantos jogos quiser. Ao todo, são 13 jogos, cada um valendo 1 ponto. Quem fizer o maior número de pontos leva a bolada. Semanalmente, todo mundo tem chance de enriquecer. Os que gostam de futebol e os que não gostam. Os que entendem e os que não entendem. Palpiteiros do Brasil, pendurem as chuteiras, fiquem ricos. (PLACAR, 1970, p. 35).

Assim como no futebol, o texto buscava alcançar $100 \%$ de adesão à Loteria Esportiva, primeiro, explicando de maneira simples, como realizar as apostas e segundo, buscando ampliar o número de apostadores a todos os brasileiros, mesmo os não aficionados por futebol (ao ampliar aos que não "gostassem" ou não "entendessem" de futebol). Além disso, o texto finalizava com o convite à real possibilidade de ascensão econômica - "fiquem ricos", que acompanhava o discurso propagado com a ideia do "Milagre Econômico", do qual a imensa maioria da população não se beneficiou.

Porém a maior parte das 'propagandas' e também as mais eficazes foram as que não traziam as marcas do governo, prática comum realizada pela AERP - Assessoria Especial de Relações Públicas / ARP - Assessoria de Relações Públicas (FICO, 1997), como sugere a seguir a análise dos dados. 
Os testes da Loteria Esportiva começaram a ser realizados na Guanabara, Estado do Rio de Janeiro, estendendo-se para São Paulo ainda em 1970 e posteriormente para o restante do país.

Sob a justificativa de aliar o futebol, a "grande paixão nacional", com a possibilidade de uma rápida ascensão social, o jogo surpreendeu pelo volume de adesão. No oitavo teste, período em que apenas o Rio de Janeiro realizava as apostas, cerca de um quarto da população carioca apostou na loteria. (FOLHA, 1994). Posteriormente, com a inclusão de São Paulo, o número de apostadores por semana subiu para aproximadamente seis milhões, o que equivalia a um terço das famílias de todo o país. (VEJA, 1970).

A aceitação dos brasileiros foi tamanha que transpôs barreiras geográficas. Enquanto as agencias oficiais estavam instaladas apenas no Rio de Janeiro e em São Paulo foi criada uma nova profissão, os chamados "corretores". Estes profissionais distribuíam os volantes, coletavam as apostas e viajavam até um dos postos para realizar as apostas. Apenas a cidade de Belo Horizonte possuía mais de 200 corretores que transportavam quase um milhão de cruzeiros por semana em apostas (VEJA, 1970).

A Loteria Esportiva continuou sendo um sucesso de público por longos anos, até que em outubro de 1982, a revista Placar denunciou a Máfia da Loteria Esportiva. A matéria de capa denunciava um esquema de corrupção envolvendo 125 nomes, dentre ele jogadores, dirigentes, árbitros técnicos e personalidades. Após tais denúncias a Loteria Esportiva perdeu a credibilidade, nunca mais recuperando o sucesso alcançado até então. (PLACAR, 1982).

Com relação às pesquisas acadêmicas sobre o tema, poucas são as investigações que tematizam a Loteria Esportiva, mesmo esta tendo sido tão explorada em determinado momento histórico. A maioria das obras que citam a Loteria refere-se a textos em que o objeto estudado é o futebol. Devido a essa limitação, um dos objetivos aqui propostos é o de sistematizar, por meio de uma revisão na literatura, quais foram os objetivos do Governo Federal com a criação e implementação da Loteria Esportiva.

Assim, organizamos a seguir os principais propósitos e objetivos do Governo Federal com relação à Loteria Esportiva, segundo revisão de literatura relizada. Interessante notar que os benefícios advindos justificam tamanho investimento e dedicação em fazer desta ação uma "jogada” de sucesso.

1 O primeiro refere-se ao mais óbvio dos propósitos: a verba advinda da venda dos bilhetes para reforçar os cofres públicos. “A loteria esportiva criada em 1970 além de 
contribuir para a manifestação ideológica do futebol foi uma fonte arrecadadora de recursos para o governo". (RIBEIRO, ALMEIDA, XAVIER, 2012, p.6 e CHAIM, 2014).

2 A Loteria Esportiva, assim como a ampliação do Campeonato Brasileiro e a Taça Independência foram utilizadas para "prolongar e ampliar pelo maior tempo possível o estado de 'êxtase' vividos pela população devido ao esporte”. (CHAIM, 2014, p. 159).

3 Este mesmo conjunto (Loteria Esportiva, Campeonato Brasileiro e Taça Independência) visava à consolidação do futebol como base de popularidade para o governo (CHAIM, 2014).

4 A Loteria Esportiva promoveu e incentivou o Campeonato Nacional, fornecendo parte dos recursos financeiros advindos das apostas para a promoção dos jogos em território nacional. (FERREIRA, 2012).

$5 \mathrm{O}$ aumento do público, principalmente nos jogos de pequenos times, foi outro incremento proporcionado pela Loteria Esportiva, uma vez que as pessoas precisavam acompanhar suas campanhas para aumentarem suas chances nas apostas. A Loteria também proporcionou destaque midiático ao campeonato, pois os meios de comunicação transmitiam e publicavam notícias sobre os jogos que compunham a loteria. O personagem da "zebrinha” criada pela rede Globo de televisão para informar os resultados dos jogos que compunham a Loteria, incentivavam ainda mais o interesse do público aos jogos do campeonato. (STEIN, 2014)

6 A Loteria Esportiva proporcionou a reafirmação e a materialização do discurso da “integração nacional” pelo futebol brasileiro. Assim, teve papel fundamental de integração dos times, por mais distantes, desconhecidos ou menores que fossem. A loteria representou "integração nacional através das apostas". (SANTOS, 2012, p.90).

7 No compasso da "unidade nacional", a Loteria Esportiva buscou promover a adesão da totalidade dos brasileiros, incentivando também as pessoas que a principio não entendiam/não gostavam de futebol a fazerem suas apostas. (STEIN, 2014; PLACAR, 1970).

8 A Loteria era "considerada uma forma de ascensão social no contexto 'Milagre Econômico', para aqueles que não eram beneficiados diretamente com os adventos do crescimento dependente e excludente" (p.75). Assim, a Loteria estava em consonância com o Milagre Econômico, promovendo ideias de otimismo, de 
prosperidade e de mobilidade social para todos. (STEIN, 2014, SANTOS, 2012, DIAS, 2014).

Os objetivos do governo Médici com a Loteria Esportiva colocam luz em nosso corpus, permitindo melhor compreensão das ideologias implícitas em tais textos e das estratégias utilizadas para a adesão da população ao jogo.

\section{Quadro teórico e procedimentos metodológicos}

Como dispositivo de análise teórico-metodológico, o artigo reivindica a Análise Crítica de Discurso (ACD), a partir das reflexões desenvolvidas por Van Djik (2008) e Fairclough (2008).

A Análise Crítica de Discurso é um tipo de análise de discurso que procura mostrar estruturas e conexões que não estejam aparentes, mas subentendidas, de difícil percepção nos textos que ela analisa. Ela procura estudar "os modos como as estruturas específicas do discurso são organizadas para reproduzir a dominação social" (VAN DJIK, 2008, p. 116). Desta forma, o discurso analisado não é considerado mero objeto autônomo, mas fruto de "uma interação situada, como uma prática social ou como um tipo de comunicação social, cultural, histórica e política" (VAN DJIK, 2008, p. 12).

Para Fairclough (2008) as abordagens críticas de discurso diferem das não críticas,

não apenas na descrição das práticas discursivas, mas também ao mostrarem como o discurso é moldado por relações de poder e ideologias e os efeitos construtivos que o discurso exerce sobre as identidades sociais, as relações sociais e os sistemas de conhecimento e crença, nenhum dos quais é normalmente aparente para os participantes do discurso (FAIRCLOUGH, 2008, p. 31-32).

A abordagem dos problemas sociais deve sempre levar em consideração que estes são baseados em relações de poder e ideologias que, por sua vez, são discursivas. Embora o discurso construa as identidades sociais, relações sociais e sistemas de conhecimento e crença, essa construção nem sempre é evidente para os participantes do processo. A função da ACD é a interpretação e explanação dos discursos em busca da explicitação das conexões e estruturas de poder que não se dão facilmente à compreensão, ou seja, sua missão é abrir, desvelar os discursos para que seja possível compreender sua posição num jogo social maior que o próprio discurso, para que possam assim ser mais bem compreendidos, mantidos ou transformados. 
No sentido metodológico, a análise de discurso "deve ser idealmente um empreendimento interdisciplinar" (FAIRCLOUGH, 2008, p. 276). Ela é uma transdisciplina que atravessa as ciências sociais, podendo ser utilizada em diversas frentes. Não existe uma única maneira de se estudar discurso, e isso possibilita o "uso de uma grande quantidade de métodos de observação, de análise e de outras estratégias para coletar, examinar ou avaliar dados, para testar hipóteses, para desenvolver teorias e para adquirir conhecimentos" (VAN DIJK, 2008, p. 13). Tais estudos utilizam "qualquer método que seja relevante para os objetivos dos seus projetos de pesquisa e tais métodos são, em grande parte, aqueles utilizados em estudos de discurso em geral" (VAN DIJK, 2008, p. 11).

Conforme o exposto, o discurso é uma forma de ação social, além de ligar-se a outras estruturas sociais. Portanto a ACD, ao desvelar relações de poder e ideologias nos discursos poderá auxiliar na transformação da realidade social, tornando-se importante ferramenta de luta política pela emancipação daqueles que são prejudicados por tais processos.

Desta forma, a ACD se mostrou apropriada para o estudo proposto neste artigo, pois permitirá trazer à luz tais relações e ideologias impressas nos discursos emitidos durante parte do regime militar. Período este que provocou danos profundos à sociedade brasileira, cujas consequências ainda se mostram presentes, mesmo passados mais de 50 anos do golpe civil-militar.

\section{1 - Corpus da pesquisa}

A realidade vivida pelos meios de comunicação de massa no pós AI-5 fez com que possuíssem características tão singulares que se tornaram difíceis as categorizações da grande maioria. Mais do que nunca, diferentes interesses e vozes mesclavam-se por traz do autoritarismo imposto pelo regime vigente. Não foi diferente com Veja, fonte de nosso objeto de estudo.

De um lado, temos a Veja que é considerada um dos meios de comunicação mais contestadores da época e aclamada nos cursos de comunicação como um exemplo de resistência, de outro temos uma Veja que tratou a causa de militantes de forma enviesada, valeu-se de discursos militares para legitimar matérias e conseguir alguns benefícios. 
Assim, durante o período aqui analisado, temos uma revista cujo editor chefe era Mino Carta, jornalista com fortes convicções, que impôs sua autonomia como condição para aceitar o cargo; porém o semanário pertencia a uma grande corporação midiática (grupo Abril), com indícios de conexão com o grupo estrangeiro Time-Life, e vivia no auge dos anos de chumbo, que subintende o controle das notícias pelo aparato censório do governo.

Estas diferentes e conflitantes vozes estiveram presentes nas edições da revista Veja durante os anos de chumbo; assim atos de "rebeldia", com notícias que desafiavam a censura, dividiam páginas com matérias que mais pareciam propagandas do governo. Este é o contexto do semanário escolhido como fonte de nosso corpus.

A escolha pela revista Veja ocorreu por ser um dos principais meios de comunicação de massa do período, bem como por seu alcance nacional.

Também se faz importante salientar que uma das principais características da grande maioria das propagandas oficiais do período foi a não utilização de 'marcas' do governo, sendo estas produzidas de maneira sutil, como nos exemplos que analisaremos. Além disto, a ideologia militar era impressa nos discursos de tudo que era veiculado no período, fosse por conivência dos meios de comunicação, por algum tipo de pressão ou pela censura.

Por este motivo, optou-se pela leitura de todo o material publicado no veículo escolhido: entrevistas, matérias ou propagandas. Todas as referências à Loteria Esportiva foram selecionadas, fossem em matérias especificas sobre o tema ou não.

O período de análise refere-se ao ano de 1970, a partir de 25 de março, data da regulamentação da Loteria Esportiva. Este levantamento permitiu avaliar a dimensão e o destaque dado pela revista ao jogo, bem como nos permitiu selecionar a matéria "Loteria Esportiva: O Jogo do Momento" para realizar a análise aqui proposta.

\section{Análise dos dados}

Ao selecionarmos um corpus para análise, pensando em uma perspectiva que contemple a ACD como procedimento teórico-metodológico, é necessário saber que tais textos não são entidades autônomas, pois eles existem em sintonia com as relações sociais que, de certa forma, representam (HINTZE, 2013). Além da interdiscursividade constante em qualquer texto, existia uma tensão discursiva típica do período histórico que envolve este estudo. Neste sentido, havia pelo menos três vozes mesclando-se continuamente nos 
meios de comunicação de massa: a voz dos jornalistas, a voz do meio de comunicação e a voz do governo, que detinha o controle de tudo o que era publicado.

No caso da revista Veja, os textos eram compostos por vozes de jornalistas, representados pelo chefe editorial Mino Carta; a voz da Editora Abril, grande corporação midiática cujo principal objetivo é o lucro; e a voz do governo, que fazendo uso do autoritarismo proibia e impunha produções e condições discursivas. Diferentes vozes, objetivos conflitantes, relações de poder e dependências: estas foram as condições de criação dos textos emitidos pela Veja durante o regime militar, sobretudo no pós-AI-5.

Os primeiros dados oriundos do levantamento proposto neste artigo demonstraram a importância dada à Loteria Esportiva pela revista Veja, um dos principais meios de comunicação de massa no período. Além disto, devido às restrições impostas às notícias no pós AI-5, os meios de comunicação normalmente veiculavam os mesmos assuntos, sendo a Loteria Esportiva um tema bastante presente também em outras publicações.

Das 41 edições que compuseram o período proposto nesta análise, $45 \%$ citavam a Loteria Esportiva em uma ou mais matérias. Destas, havia matérias cujo tema central era a Loteria Esportiva e outras que tratavam dos mais variados assuntos e a citava "sutilmente", transmitindo ideias positivas, como, por exemplo, o benefício que os esportes receberiam e a possibilidade de rápida ascensão financeira.

Além de duas matérias de capa (em um período de oito meses!) as referencias à Loteria Esportiva foram realizadas nas mais diversas sessões da revista, a citar: Esporte, Cartas, Eleições, Economia e Negócios, Comportamento, Pesca, Televisão, Investimentos, Brasil, Educação além de entrevista e peça publicitária. Essa diversidade constata que além das matérias especificas sobre o tema, em que fica claro o incentivo à adesão ao jogo, havia o interesse na naturalização da loteria como algo positivo, uma vez que o tema foi inserido nas diversas notícias cotidianas.

Dentre as matérias encontradas nesta seleção, foi escolhida a "Loteria Esportiva: O Jogo do Momento" como objeto de nossa análise. Esta não foi a única matéria de capa sobre o assunto durante o período, porém apresentou características discursivas importantes aos propósitos deste artigo, que serão explicitadas a seguir. Antes, vejamos a capa: 


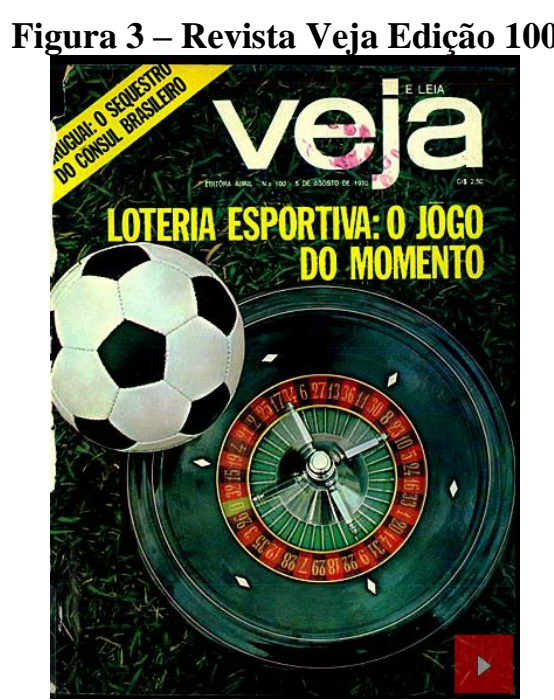

Fonte: Acervo Revista Veja, 1970

A matéria foi publicada em agosto de 1970, no auge dos anos de chumbo, logo após a Copa do Mundo de 1970 e os primeiros jogos da Loteria Esportiva, que teve seu primeiro teste na Guanabara em abril de 1970 (LOTERIAS CAIXA, 2011). A matéria estava localizada na sessão "Vida Moderna" (sessão esta que indica notícias sobre temas cotidianos - e que se utiliza do termo 'moderna' que parece trazer uma conotação de positividade à vida que a revista quer mostrar e que vai em direção aos desígnios discursivos e políticos do 'Estado de Médici'), com o título "O jogo do futebol: Loteria esportiva, sucesso antes de começar".

Assim como os títulos, tanto da Capa (Loteria Esportiva: O Jogo do Momento), quanto da matéria ( $\mathrm{O}$ jogo do futebol: Loteria esportiva, sucesso antes de começar), as sete páginas são redigidas com o mesmo 'entusiasmo'. Também são verificadas estratégias discursivas de incentivo ao consumo da Loteria Esportiva/Futebol e aceitação do governo por intermédio de tais temas, como veremos a seguir.

Logo nos primeiros parágrafos da matéria, é constatado o uso de clichês relacionados ao Brasil como "país do futebol" e o futebol como "paixão nacional" para compor o texto. Trechos como "o brasileiro é doido por futebol e a paixão do jogo é universal" (VEJA, 1970, p. 48), a loteria "nasceu do encontro de duas paixões brasileiras: o futebol e o jogo" e "nós já tínhamos o melhor futebol do mundo. E agora possuímos também a melhor das loterias esportivas", promoviam a intensificação da relação "futebol" e "Loteria Esportiva". O aparato do Estado, como visto anteriormente, criou 
uma ampla estrutura discursiva em torno do tema "futebol", e ao criar a Loteria Esportiva, buscaram valer-se desta estrutura já existente para "emplacar” o novo jogo.

O ideal de "unidade nacional" foi amplamente utilizado pelos militares durante o regime servindo aos mais diversos propósitos de controle ideológico. Sabe-se que esse ideal foi forjado lenta e gradualmente, buscando dar sustentação ao regime. Vários foram os meios para a sua promoção, como foi o caso do uso da televisão que "teve papel inquestionável no propósito de integrar a população brasileira em torno do espetáculo de consumo de bens matérias" (ANDRADE, 2003, p. 63), mesmo em um período em que a desigualdade social e a concentração de renda eram crescentes.

A marca impressa no corpus estudado sugere que, assim como utilizado em torno do futebol, a "unidade nacional" foi também utilizada nos enunciados referentes à Loteria Esportiva.

O primeiro fragmento destacado refere-se a uma citação feita da fala do chefe do departamento do concurso "Todo mundo quer apostar, desde o presidente da República, o ministro da Fazenda e o governador do Estado, até o varredor de rua" (VEJA, 1970, p. 48). O trecho, além de associar a imagem do presidente da República como um homem do povo, o iguala hierarquicamente ${ }^{5}$ quando o propósito é a "unidade nacional". Assim, como no "hino oficial" da copa do mundo de 1970, que dizia "todos juntos, vamos pra frente Brasil", o texto exprime a ideia de que, do presidente da república ao varredor de rua, estamos todos juntos, somos todos iguais, somos todos brasileiros e, especificamente neste caso, todos podemos e queremos jogar.

Esta proposta de unidade deixou outra marca no texto, conforme pode ser observado no trecho "a Loteria Esportiva será vitoriosa em São Paulo e, depois, em todo o país", abrangendo geograficamente a totalidade do país.

As palavras "sucesso" e "vitoriosa" foram por inúmeras vezes retomadas no texto, inclusive no subtítulo da matéria "O Jogo do futebol: Loteria Esportiva, sucesso antes de começar". Assim como demais palavras de sentido positivo compõem as frases que falavam sobre a Loteria Esportiva e do governo em exercício, em contraposição, adjetivos depreciativos como "complicado", "ultrapassados", "perigosos", entre outros, foram os escolhidos para definir os demais jogos (como, por exemplo, o jogo do bicho) e governos. O processo discursivo, por meio da desvalorização, do "outro" ressaltava ainda mais os

\footnotetext{
${ }^{5}$ É importante salientar valor da hierarquia nos meios militares. Uma das justificativas do golpe civilmilitar de 1964 foi o "não respeito" à hierarquia militar por João Goulart.
} 
aspectos positivos atribuídos à Loteria Esportiva (sempre em conexão com o governo vigente). A Loteria é apresentada como melhor opção pelos mais variados aspectos, conforme será expresso no decorrer desta análise.

O processo de legitimação da Loteria Esportiva procurou identificar o brasileiro como um apostador nato, que preferia a segurança da institucionalidade aos riscos de jogos informais. Estas características construídas estão na base semântica do texto, que afirma (e reafirma) tais características como constitutivas da personalidade do brasileiro. A seguir são apresentados dois trechos relevantes da matéria que permitirão tecer observações e realizar uma análise discursiva sobre o tema.

\section{Quadro 1}

“(...) todos os brasileiros se parecem um pouco com os frequentadores do Estádio da Fonte Nova, em Salvador: em dia de jogo, os torcedores fazem bolo para ver que time entra primeiro em campo, que jogador se machuca antes, quem marca o primeiro gol, quanto os vendedores de pastel, balas, sorvetes ou amendoim vão vender. Uma das vantagens da Loteria Esportiva é diminuir essas apostas paralelas, ilegais e perigosas, e, principalmente, acabar com o jogo do bicho: $60 \%$ do seu movimento já tinha sido liquidado na Guanabara com as medidas repressivas após o Ato 5. E o Bolão terminou com mais de $20 \%$ do bicho (o Jóquei Clube e a Loteria Federal nada sofreram até agora). Mais ainda: o concurso permitirá, por ser simples e barato, que o espírito de apostador do brasileiro possa se satisfazer sem maiores riscos.” (VEJA, 1970, p.52).

"O apostador-padrão prefere jogar no certo (ou no legal) do que arriscar no duvidoso. Por exemplo: ele não gosta de rifas, carnes, sorteios, álbuns de figurinhas, concurso de prêmios - ainda que beneficentes. Mas possui toda a confiança no sucesso e nos objetivos da nova Loteria Esportiva. (...). Com a Loteria Esportiva não existe problema: $80 \%$ dos compradores confirmam que participarão do novo jogo. Sem esquemas programados, sem métodos infalíveis - e sem gastar muito dinheiro (nos oito primeiros testes, efetuados na Guanabara, a média de apostas foi de $\mathrm{Cr} \$ 3,80$ por pessoa): todos acreditam no caráter aleatório da sorte." (VEJA, 1970, p.53).

As marcas textuais da "Unidade Nacional" fazem-se novamente presente nos trechos destacados acima. Na primeira e na última frase lemos "todos os brasileiros" e “todos acreditam no caráter da sorte", integrando a totalidade do povo e apresentando tais 
características como componentes da brasilidade (assim como o discurso do futebol, com sucesso, identificou o esporte como uma "paixão nacional" reafirmando e fixando no imaginário popular tal esporte como componente de sua cultura).

Assim, a matéria procurou, por diversos momentos, a naturalização da Loteria Esportiva como um componente da identidade brasileira. No trecho em destaque os brasileiros são descritos como possuidores de um “espirito de apostador". Existem outros fragmentos que transpassam este sentido, como quando é dito, logo no primeiro parágrafo, que o Brasil é um "país de apostadores contumazes" (VEJA, 1970, p. 48) ou quando é citado que a loteria demonstra a "vigorosa amostra do interesse nacional pelo jogo" (VEJA, 1970, p. 48).

Ao mesmo tempo em que o enunciado procurou "convencer" que o gosto pelo jogo era uma característica nata de "todos" os brasileiros, ele citou algumas "preferências" do povo em uma tentativa de promover conexão com a Loteria Esportiva, em detrimento dos jogos não institucionalizados. Assim, foram expressas inúmeras tentativas de convencimento de que o brasileiro prefere a segurança ao risco, que prefere o legal ao ilegal.

A primeira frase da matéria já afirmava: "Sempre foi uma tendência normal do brasileiro preferir a segurança à aventura”, esta ideia foi repetida ao longo do texto, como no excerto citado acima "o apostador-padrão prefere jogar no certo (ou no legal) do que arriscar no duvidoso". Assim, o texto aponta para a existência do legal e do ilegal, e afirma que o brasileiro gosta do que é "legal". Desta forma, segundo o discurso analisado, o espirito apostador do brasileiro precisa ser canalizado para o institucionalizado, caso contrário, ele incorre no risco de apostar nos jogos "perigosos" fora da institucionalização do Estado.

O irônico do trecho exposto é a contradição em que o texto incorre ao expor a afirmativa construída de que o brasileiro prefere os jogos legais (ou seja, todos institucionalizados: Jóquei Clube, Loterias Esportivas e Federais) aos ilegais. Se esta é uma preferência nata dos brasileiros, porque foram necessárias “medidas repressivas após o Ato $5 \%$ ?

No excerto apresentado, os dois tipos de apostas são assim construídas: as legais são "simples", "baratas" e "sem maiores riscos" e as ilegais, como por exemplo, apostar quanto os "vendedores de pastel, balas, sorvetes ou amendoim vão vender" são descritas como "paralelas", "ilegais" e "perigosas". Esta depreciação realizada com os jogos não 
institucionalizados é construída por discurso pejorativo, como no caso do jogo do bicho que tem as apostas registradas em "escusos pedacinhos de papel branco com números anotados e assinatura pouco legível" (VEJA, 1970, p. 52).

Para finalizar a análise do Quadro 1, cabe um olhar cuidadoso ao seguinte trecho "Sem esquemas programados, sem métodos infalíveis (...): todos acreditam no caráter aleatório da sorte.”. Neste contexto, o “jogo de azar", criticado e até proibido em governos anteriores, foi discursivamente transformado em "jogo de sorte" pelos governos militares.

No processo de legitimação impresso no texto, não podemos deixar de destacar dois trechos que apontam certa necessidade de ênfase do enunciador. São eles:

1 "Esta semana a Loteria Esportiva vai dar um novo e grande passo na sua curta e vitoriosa carreira." (VEJA, 1970, p.51, grifo dos autores).

2 "Dos funcionários destas casas, oitocentos fizeram treino intensivo para aprender a lidar com o Bolão duas horas por dia, durante quatro dias". (VEJA, 1970, p.51, grifo dos autores).

Em uma tentativa de aceleração da aceitação da Loteria, temos um deslocamento da noção do tempo. Assim, em menos de quatro meses do início dos testes (!) da Loteria, foi constatada pelo enunciador que o jogo tinha "vitoriosa carreira"6. E um "treino intensivo”, neste contexto, é realizado em 'intermináveis' duas horas pelo 'longo' período de quatro dias.

Chaim (2014, p. 54), ao falar sobre o futebol como estratégia de governo no pós AI-5, cita que o esporte "passou a possuir o papel de ser agente do fortalecimento da identificação civil dos cidadãos brasileiros com a nação". Neste texto ocorreu a materialização desta "identificação civil" por meio do futebol, sendo utilizada a preferência esportiva como um caráter distintivo, relacionado a demais descrições da pessoa, como, por exemplo, a profissão.

Ao descrever "Aurélio Castelo Branco, superintendente da Administração do Serviço da Loteria Federal (45 anos, flamenguista).” ou “José Gabrielense Gomes Duarte, chefe do Departamento de Concursos - torcedor do São Cristóvão." (p.48, grifo dos autores), o texto apresenta nos fragmentos grifados um caractere da identidade pessoal de cada cidadão, inserindo esta informação como um item constitutivo da personalidade das pessoas. Assim, uma informação aparentemente informal, na verdade constrói o mundo

\footnotetext{
${ }^{6}$ Lembrando que o vocábulo "carreira" subintende-se a ideia de tempo, de projeção profissional.
} 
idealizado pelo governo e demais grupos de interesses, mundo este onde "todos" devem ter suas profissões e preferências futebolísticas.

A questão das verbas advindas das apostas foi outro tema citado no texto que merece ser aqui destacado e analisado.

Trechos como "no Brasil a Loteria Esportiva tem de ser dirigida pelo governo" e “Aurélio Castelo Branco continuou guardando a convicção íntima de que não interessava ao Brasil pagar expressa a 'luta' do governo para que a loteria fosse nacional" apresentam um discurso ufanista propagado pelo governo na defesa de uma "loteria brasileira", os aspectos positivos expressos no texto eram a não evasão de divisas com os pagamentos de "técnicos, máquinas e royalties ao estrangeiro".

Esta "preocupação" é no mínimo irônica, se considerarmos que tais governos permitiram a penetração das multinacionais em condições econômicas nada favoráveis ao Brasil (DREIFUSS, 1981). Definitivamente, esta era a última das preocupações dos governos e, no caso específico da Loteria Esportiva, este argumento foi utilizado para promover a ideologia e as ações governamentais, e principalmente, escamotear a verdadeira intenção em lucrar ainda mais com a arrecadação ${ }^{7}$.

$\mathrm{O}$ texto ainda apresenta as instituições beneficiadas com tais recursos, como o MEC - Ministério da Educação e Cultura, que "pretende aplicar esse dinheiro no Mobral - Movimento Brasileiro de Alfabetização”, o CND - Conselho Nacional dos Desportos que "financiará material, instalações e viagens de entidades esportivas amadoras e bolsas de estudo para técnicos no exterior” e a LBA - Legião Brasileira de Assistência que "gastará o dinheiro que recebe da Loteria Esportiva especificamente na ajuda de crianças e parturientes que não gozem de direitos junto ao INPS e em programas gerais de assistência a família, infância e adolescência.” (VEJA, 1970, p.50).

A aplicação de parte dos recursos arrecadados com a loteria em questões sociais também não deixa de ser lucrativa para o governo, uma vez que oferecer educação e saúde é uma obrigação do Estado. Além disto, o apelo social descrito no texto representou outra fonte de argumentação em prol da adesão ao jogo, como ressaltado na fala de Aurélio Castelo Branco: “é importante que o apostador entenda que os 3 ou 4 cruzeiros dedicados ao seu prognóstico, mesmo que ele não ganhe nada, contribuem decisivamente para uma série de obras assistenciais e educacionais". (VEJA, 1970, p. 50).

\footnotetext{
${ }^{7}$ Lembrando que, conforme exposto anteriormente, o governo brasileiro ao não seguir os padrões europeus, aumentou a arrecadação dos cofres públicos, cobrando, ainda, imposto sobre o prêmio dos ganhadores.
} 
O corpus escolhido para esta análise se mostrou tão rico que foi necessário selecionar os fragmentos mais relevantes para cumprir com os objetivos aqui propostos. Assim o texto nos possibilitou, a partir da reflexão sobre os objetivos militares com a criação da Loteria Esportiva, apresentar parte da estratégia utilizada no período para a adesão da população pelo uso das Loterias Esportivas.

\section{Considerações Finais}

Este artigo cumpriu seu propósito apresentando os principais objetivos e benefícios do governo Médici com a criação da Loteria Esportiva, bem como parte da estratégia utilizada para a adesão da população ao uso da Loteria Esportiva. Por meio dos discursos impressos na revista Veja mapearam-se também algumas das estratégias utilizadas para legitimar a Loteria Esportiva e, consequentemente o Estado autoritário.

A principal caraterística do governo Médici foi o endurecimento do regime: torturas, assassinatos e impunidade são palavras que remetem facilmente a tal período. Juntamente com o endurecimento do regime, houve uma intensificação nas propagandas político-ideológica, com destaque ao futebol.

A Loteria Esportiva, mesmo representando quantia substancial aos cofres públicos, teve seu maior propósito relacionado a auxiliar a sustentação ideológica de tal governo. Assim, o "jogo do futebol” foi peça importante na engrenagem montada para sustentar discursivamente o regime, disseminando o gosto dos brasileiros pelo futebol, difundindo o "milagre econômico" e o senso de "integração nacional", promovendo o Campeonato Nacional, entre outros.

Desta forma, o grande interesse em promover a adesão da população ao jogo não era apenas, como inicialmente poderia parecer, o consumo material da Loteria. O consumo simbólico era o seu maior propósito, pois, consumindo a loteria o povo estaria "consumindo" e partilhando valores do Estado.

Conforme exposto, para alcançar tais objetivos o governo valeu-se dos mecanismos de comunicação e procurou manter o assunto constantemente na mídia. No corpus estudado verificou-se que em $45 \%$ das edições havia ao menos uma menção à Loteria Esportiva, dentre matérias especificas sobre o tema (incluindo duas matérias de Capa) e inserções nos mais variados temas. Segundo a análise do material, foi possível notar que além do incentivo à adesão ao jogo, havia o interesse na naturalização da loteria como algo positivo, sendo o tema inserido em diversas notícias cotidianas. 
Dentre as estratégias discursivas apresentadas neste artigo, vale ressaltar que o conceito de Unidade Nacional foi constantemente retomado, assim como buscou-se fazer com que características inerentes a Loteria Esportiva se transformasse em componentes da Identidade Nacional, apresentando tais características como componentes da brasilidade. No texto analisado ainda foi possível observar a transformação discursiva de um "jogo de azar" (denominação utilizada por antigos governos) em um "jogo de sorte", para assim servir aos interesses dos governos militares.

Por fim, considerando a carência de trabalhos acerca dos temas aqui tratados e a existência de lacunas a serem preenchidas, esperamos que este artigo possa contribuir para um melhor entendimento deste emblemático período e venha colaborar com pesquisadores que objetivem trilhar por este caminho.

\section{Referências Bibliográficas}

CHAIM. Aníbal Renan Martinot. A Bola e o Chumbo: Futebol e Política nos anos de chumbo da Ditadura Militar Brasileira. São Paulo, 163 p. Dissertação de Mestrado Faculdade de Filosofia, Letras e Ciências Humanas - FFLCH, Universidade de São Paulo, 2014.

CHAIM. Aníbal Renan Martinot. O impulso ao futebol nos anos de chumbo. Disponível em: http://www.cartamaior.com.br/?/Editoria/Politica/O-impulso-ao-futebol-nos-anosde-chumbo /4/30661. Aceso em: 13/07/2014

CHIAVEnATO, Júlio José. O Golpe de 64 e a Ditadura Militar. 4 ed. São Paulo: Moderna, 1995.

DECRETO-LEI. Decreto $\mathbf{n}^{\mathbf{0}}$ 66.118, de 26 de Janeiro de 1970. Disponível em: http://www.planalto.gov.br/ccivil_03/decreto/1970-1979/D66118.htm. Acesso em: 10/02/2014.

D’ARAÚJO, Maria Celina. O AI-5. Fundação Getúlio Vargas. Disponível em: http://cpdoc.fgv.br/producao/dossies/FatosImagens/AI5. Acesso em 15/02/2010.

DREIFUSS, René Armand. 1964: A Conquista do Estado. Ação Política, Poder e Golpe de Classe. Petrópolis, Rio de Janeiro, 1981.

FAIRCLOUGH, Norman. Discurso e mudança social. Brasília: Editora Unb, 2008.

FERREIRA, João Fernando Pelho. A política do Governo Médici e a Revista Brasileira de Educação Física. Anais do XXI Encontro Estadual de História -ANPUH-SP Campinas, setembro, 2012.

FICO, Carlos. Reinventando o Otimismo: Ditadura, propaganda e imaginário social no Brasil. Rio de Janeiro: Fundação Getúlio Vargas, 1997.

FOLHA DE S. PAULO. Loteria Esportiva é lançada no Rio de Janeiro. Disponível em: http://www1.folha.uol.com.br/fsp/1994/7/17/cotidiano/10.html. Acesso em: 15/03/2014.

GARCIA, Nelson Jahr. Propaganda: Ideologia e Manipulação. eBook: Rocket Edition, 2005. 
GASPARI, Elio. A Ditadura Envergonhada. São Paulo: Companhia das Letras, 2002. GRAF, Marilia. Propaganda de lá pra cá. São Paulo: IBRASA, 2003.

GUSTAVO, Miguel. Pra Frente Brasil. Disponível em: http://www.letras.com.br/\#!miguel-gustavo/pra-frente-brasil. Acesso em 21/02/2014.

HABERT. Nadine. A Década de 70: Apogeu e Crise da Ditadura Militar Brasileira. 3 ed. São Paulo: Ática, 2003.

LOTERIAS CAIXA. Carta de Serviços. Disponível em: http://www.gespublica.gov.br/ biblioteca/pasta.2011-01-03.6819661654/carta_de_servicos_Fevereiro_baixa.pdf. Acesso em 10/02/2014.

LUNA, Paulo. No Compasso da Bola. São Paulo: Irmãos Vitale, 2011.

MARIUZZO, Patrícia. Pra frente Brasil! Copa do mundo e ditadura no Brasil. Disponível em: http://www.univesp.ensinosuperior.sp.gov.br/preunivesp/116/pra-frente-brasilcopa-do-mundo-e-ditadura-no-brasil.html. Acesso em 13/12/2013.

MARCONI, Paolo. A Censura Política na Imprensa Brasileira: 1968-1978. São Paulo: Global, 1980.

PLACAR.

http://books.google.com.br/books?id=MbkgXNe71hcC\&printsec

$=$ frontcover $\& \mathrm{hl}=\mathrm{ptBR} \& \mathrm{rview}=1 \&$ source $=\mathrm{gbs} \_\mathrm{ge} \_$summary_r$\&$ cad $=0 \# \mathrm{v}=$ onepage $\& \mathrm{q} \& \mathrm{f}$ $=$ falae. Acesso em: 13/04/2014.

RIBEIRO, Karoline; ALMEIDA, Marco Antonio; XAVIER, Eduardo. O processo civilizador e a interferência política no esporte: o uso do futebol como prática de lazer durante o regime militar brasileiro. Revista Digital. Buenos Aires, Año 16, № 164, Enero de 2012.

RINALDI. Wilson. Futebol: Manifestação Cultural e Ideologização. Revista de Educação Física/ UEM, V. 11, n. 1, p. 167-172, 2000.

SANTOS, Daniel de Araújo dos. Futebol e Política: A criação do campeonato nacional de clubes. Rio de Janeiro, 150 p. Dissertação de Mestrado - Centro de Pesquisa CPDOC.

STEIN, Leandro. Ditadura: Da criação do Brasileirão aos elefantes brancos, como o futebol entrou no Plano de Integração Nacional. Disponível em: http://trivela.uol.com.br/da-criacao-brasileirao-aos-elefantes-brancos-como-o-futebolentrou-plano-de-integracao-nacional/. Acesso em: 25/04/2014.

VEJA. Acervo Digital. Disponível em: http://veja.abril.com.br/acervodigital/home.aspx. Acesso em 14/02/2013.

VINCENZO, José Eduardo de. Loteria Esportiva: Uma Paixão de Muitos. Brasília: LGE editora, 2006.

VAN DIJK, Teun. Discurso e Poder. São Paulo: Contexto, 2008. 


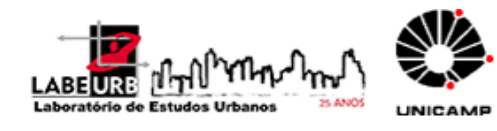

\section{Para citar essa obra:}

FINO, Patrícia; HINTZE, Helio. Jogada de Médici: o uso da loteria esportiva pelo regime militar brasileiro. In: RUA [online]. nº. 23. Volume 2, p. 267 - 289 - e-ISSN 2179-9911 - Novembro/2017. Consultada no Portal Labeurb - Revista do Laboratório de Estudos Urbanos do Núcleo de Desenvolvimento da Criatividade.

http://www.labeurb.unicamp.br/rua/

Capa: Revista Veja Edição 100 Fonte: Acervo Revista Veja, 1970

\section{Laboratório de Estudos Urbanos - LABEURB}

Núcleo de Desenvolvimento da Criatividade - NUDECRI

Universidade Estadual de Campinas - UNICAMP

http://www.labeurb.unicamp.br/

\section{Endereço:}

\section{LABEURB - LABORATÓRIO DE ESTUDOS URBANOS \\ UNICAMP/COCEN / NUDECRI \\ CAIXA POSTAL 6166}

Campinas/SP - Brasil

CEP 13083-892

Fone/ Fax: (19) 3521-7900

Contato: http://www.labeurb.unicamp.br/contato 